\title{
REFRIGERANTE DE FRUTAS VERMELHAS: DESENVOLVIMENTO, TESTE FÍSICO-QUÍMICO, MICROBIOLÓGICO E SENSORIAL
}

\author{
M. L. LAMOUNIER ${ }^{1}$, R. L. SILVA ${ }^{2}$, M. R. V. CARDOSO ${ }^{3}$, M. L. MAGALHÃES ${ }^{4}$
}

Instituto Federal de Minas Gerais Campus Bambuí ${ }^{1,2,3}$, Instituto Federal do Triângulo Mineiro Campus Uberaba ${ }^{4}$ maisalamounier@yahoo.com.br ${ }^{4}$

Artigo submetido em 31/03/2015 e aceito em 24/06/2019

DOI: 10.15628/holos.2019.2926

\section{RESUMO}

Uma nova abordagem vem sendo dada aos refrigerantes que podem apresentar múltiplas funções e satisfazer o desejo do consumidor moderno por produtos saborosos e saudáveis. As frutas vermelhas apresentam diversas propriedades funcionais que têm sido amplamente relacionadas aos seus altos níveis de compostos bioativos que auxiliam na redução de doenças. Este trabalho teve por objetivo elaborar três formulações de refrigerantes que foram diferenciados devido à adição de diferentes porcentagens de açúcar e sucralose (denominados R1 controle, R2 light, R3 diet), enriquecidos com polidextrose e saborizados com frutas vermelhas. Foram realizadas análises microbiológicas (coliformes totais e staphylococcus), físico-químicas ( $\mathrm{pH}$, acidez total titulável, sólidos solúveis totais, cinzas e antocianinas), bem como teste de aceitação e intenção de compra. As análises estatísticas foram realizadas pelo
\end{abstract}

software SISVAR e utilizou-se o teste Tuckey, ao valor nominal de $5 \%$. Como resultado, foi detectado diferença $(\mathrm{P}<0,05)$ para $\mathrm{pH}$, acidez, SST, umidade e cinzas em todas as formulações. Na avaliação sensorial, quando verificado o atributo aparência, os tratamentos R1 e R2 não apresentaram diferença significativa, já para sabor e aspecto global, a única formulação que se diferenciou foi a R3 sendo que as demais receberam conceito "gostei" (notas acima de 7,0). Quando questionados sobre a intenção de compra, as formulações R1, R2 e R3 não apresentaram diferença significativa e receberam nota 3 (talvez comprasse/talvez não comprasse) provavelmente pela utilização de ingredientes não tão usuais. Conclui-se, que os refrigerantes apresentam potencial de mercado e atendem a demanda dos consumidores que buscam produtos atraentes e saudáveis.

PALAVRAS-CHAVE: bebidas funcionais, fibras alimentares, berrys.

\section{DRINKS BERRIES: DEVELOPMENT, CHEMICAL-PHYSICAL TEST, MICROBIOLOGICAL AND SENSORY}

\begin{abstract}
A new approach has been given to soft drinks that may have multiple functions and satisfy the desire of the modern consumer for tasty and healthy products. The berries have several functional properties that have been largely related to its high levels of bioactive compounds that help reduce diseases. This study aimed to develop three soft drink formulations were different due to the addition of different percentages of sugar and sucralose (called R1 control, light R2, R3 diet), supplemented with polydextrose and flavored with red fruits. Microbiological analyzes were performed (total coliforms and Staphylococcus), physico-chemical ( $\mathrm{pH}$, titratable acidity, soluble solids, ash and anthocyanins) and acceptance testing and purchase intent. Statistical analyzes were
\end{abstract}

performed by SISVAR software and used the Tukey test, the nominal value of $5 \%$. As a result, a difference was observed $(\mathrm{P}<0.05)$ for $\mathrm{pH}$, acidity, TSS, moisture and ash in all formulations. In sensory evaluation, when checked the appearance attribute, R1 and R2 treatments did not differ significantly, as for taste and overall aspect, the unique formulation that differed was the R3 while the others received concept "liked" (notes above 7,0 ). When asked about the intention to purchase, the formulations R1, R2 and R3 did not differ significantly and were graded 3 (maybe buy / may not buy) probably by the use of not so usual ingredients. It follows that soft drinks have market potential and meet the demand of consumers looking attractive and healthy products.

KEYWORDS: functional beverages, dietary fiber, berrys. 


\section{INTRODUÇÃO}

O refrigerante se destaca entre os alimentos de maior consumo na atualidade pela sua capacidade de proporcionar saciedade e refrescância. Está cada vez mais frequente na mesa do brasileiro, sendo um dos alimentos atuais mais consumidos. Talvez mal interpretado por conter carga energética de pouca importância nutricional em grande quantidade, a ANVISA classifica o refrigerante como bebida com baixo teor nutricional.

No entanto, o refrigerante pode agir como um alimento funcional auxiliando na nutrição e manutenção do organismo, através da adição de sucos de frutas ricos em vitaminas, minerais, fibras e principalmente, compostos bioativos.

A partir do ponto de vista nutricional e funcional foi escolhido o sabor de frutas vermelhas para saborizar o refrigerante. Elas são popularmente conhecidas por suas características sensoriais convidativas e também por sua ação antioxidante proveniente dos compostos fenólicos presentes. Como exemplo de frutas vermelhas, cita-se a amora-preta (Rubus fruticosus), o cranberry (Vaccinium macrocarpon), o morango (Fragaria vesca) e a uva roxa (Vitis viniferaL, no qual um crescente corpo de evidências epidemiológicas e clínicas sugerem um papel benéfico dessas frutas na redução das incidências e mortalidade por certos tipos de câncer.

O enriquecimento com polidextrose é uma forma de agregar valor ao produto devido suas propriedades funcionais, por ser reconhecida como uma fibra alimentar altamente solúvel, de baixo valor calórico e, por ser um agente de volume. É utilizada em diversas formulações como substituto de açúcares e gorduras e é reconhecida como um ingrediente prebiótico, pois estimula o crescimento de bifidobactérias do trato intestinal e auxilia na redução dos níveis de colesterol e glicose no sangue.

Este trabalho teve por objetivo elaborar três diferentes formulações de refrigerantes enriquecidos com polidextrose, saborizados com polpa de frutas vermelhas e com diferentes teores de açúcar e sucralose, bem como avaliar as características físico-químicas, microbiológicas e sensoriais dos mesmos.

\section{REVISÃO BIBLIOGRÁFICA}

\subsection{Alimentos funcionais}

Devido à ampla divulgação pela imprensa em geral da relação entre alimentação e saúde, a preocupação da sociedade ocidental com os alimentos tem aumentado de forma exponencial.

A possibilidade do uso de alimentos na redução de risco de doenças crônicas não transmissíveis tem sido assunto constante em eventos na área de alimentação e nutrição. Suprindo a demanda por health y foods (comidas saudáveis), surgiram os alimentos funcionais com vistas a unir tecnologia pelo desenvolvimento de novos produtos e benefícios saudáveis. A maior atenção que tem sido dada a este tipo de informação ocorre pelo fato dos consumidores de Alimentos 
Funcionais estarem cada vez mais conscientes da ligação entre saúde e nutrição, ou seja: a preferência à prevenção e não à cura de doenças (DE BARCELLOS et al., 2009)

Segundo Borges (2004), os alimentos funcionais devem exercer um efeito metabólico ou fisiológico que contribua para a saúde física e para a redução do risco de desenvolvimento de doenças crônicas. Nesse sentido, devem fazer parte da alimentação usual e proporcionar efeitos positivos, obtidos com quantidades não tóxicas e que exerçam tais efeitos mesmo após a suspensão da ingestão e que não se destinem a tratar ou curar doenças, estando seu papel ligado à redução do risco de contrair doenças.

Alimentos funcionais são definidos como qualquer substância ou componente de um alimento que proporciona benefícios para a saúde, inclusive a prevenção e o tratamento de doenças. Esses produtos podem variar de nutrientes isolados, produtos de biotecnologia, suplementos dietéticos, alimentos geneticamente construídos até alimentos processados e derivados de plantas (ANJO, 2004).

A ANVISA (Agencia Nacional de Vigilância Sanitária) é o órgão regulatório no Brasil e define os alimentos funcionais de acordo com diretrizes criadas para sua caracterização. A Portaria no 398, de 30/04/99, define alimento funcional como "todo aquele alimento ou ingrediente que, além das funções metabólicas normais básicas, quando consumido como parte da dieta usual, produza efeitos metabólicos e/ou fisiológicos e/ou efeitos benéficos à saúde, devendo ser seguro para consumo sem supervisão médica" (BRASIL, 1999).

\subsection{Frutas vermelhas}

As frutas vermelhas, também conhecidas como "Berries", apresentam micro e macronutrientes em quantidades expressivas, incluindo vitaminas, minerais, ácido fólico e fibras. No entanto o destaque para seu consumo é atribuído as suas diversas propriedades funcionais que têm sido amplamente relacionados aos seus altos níveis de compostos bioativos como da diversidade de tais compostos (SEERAM, 2008).

De acordo com Brown (2002), a família Rosaceae é ampla e diversa, incluindo em torno de 75 gêneros e mais de 1200 espécies. Os membros desta família são valiosos por seus frutos e produtos derivados. As frutas vermelhas, como são geralmente conhecidas, têm sido usadas frequentemente pela indústria de alimentos. Os produtos manufaturados, tais como sucos, néctares, sorvetes e geléias utilizam a polpa dessas frutas como matéria-prima.

Devido ao seu teor de compostos fenólicos e flavonoides, as frutas vermelhas apresentam potencial antioxidante elevado (STONER; WANG; CASTRO, 2008). Os fitoquímicos estão altamente concentrados (especialmente os polifenóis como as antocianinas e os elagitaninos). Estes compostos têm sido associados com a capacidade antioxidante, proteção à peroxidação lipídica, atividade anti-inflamatória, atividade anticarcinogênica, prevenção da obesidade e outros (SCOTTI et al., 2007). Comparadas com a maioria das frutas, as vermelhas tem altas concentrações de antocianinas (BORDIGNON et al., 2009).

Frutas vermelhas apresenta uma das mais importantes fontes dietéticas de polifenóis como antocianinas, flavonóis, flavan-3-óis e os derivados do ácido benzoico e cinâmico. Numerosos 
estudos in vitro têm relatado os vários efeitos na saúde que essas frutas podem ter quando fazem parte da dieta humana, entre os quais a alta atividade contra os radicais livres e a capacidade de inibir as lipoproteínas de baixa densidade em humanos e a oxidação dos lipossomas (BORDIGNON et al., 2009).

Vários compostos lipofílicos e hidrofílicos são encontrados em frutas vermelhas, cujas propriedades biológicas têm sido atribuídas aos altos níveis e ampla diversidade de compostos fenólicos. Porém, acredita-se que o efeito complementar, aditivo e/ou, sinérgico resultante dos diversos componentes seja o responsável pelas propriedades biológicas benéficas ao invés de uma única classe ou composto químico (FERREIRA et al., 2010).

\subsubsection{Amora-Preta}

A amoreira-preta (Rubus sp.) é uma espécie arbustiva de clima temperado, de porte ereto ou rasteiro, que produz frutas agregadas com cerca de 4 a 7 gramas, de coloração negra e sabor ácido a doce-ácido (ANTUNES, 1999; ANTUNES, 2002).

A Amora-preta (Rubus ulmifolius Schott) (Figura 1) pertence à família das Rosáceas, possuindo importância econômica no Hemisfério Norte. O maior produtor na América do Sul é o Chile, cuja produção é destinada principalmente à exportação. No Brasil, o cultivo tem maior importância nos estados do Rio Grande do Sul, Santa Catarina e Paraná (RASEIRA; SANTOS, 1992).

Além do consumo in natura, o grande mercado para produtos de amora-preta é gerado a partir do suco clarificado e concentrado, usado como base na elaboração de uma vasta gama de produtos, como caldas para sorvetes, geleias, xaropes, bebidas alcoólicas, refrescos e misturas com sucos de outras frutas (FERREIRA et al., 2010).

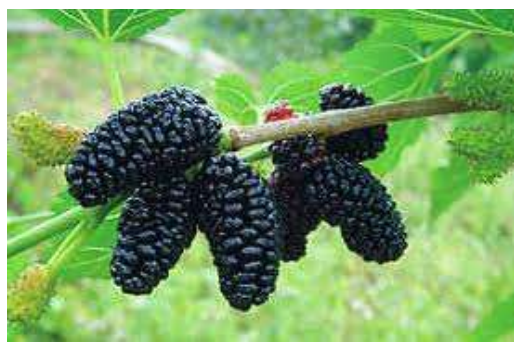

a)

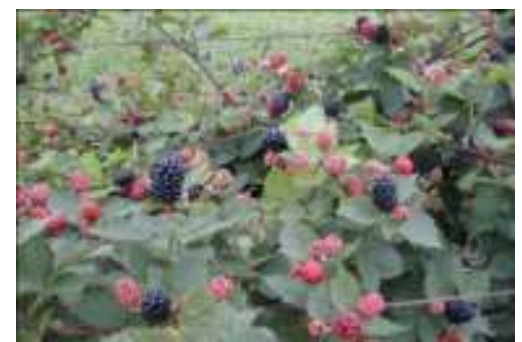

b)

Figura 1: Frutos de amoreira-preta (Rubus ulmifolius Schott) Fonte: Google imagens

O fruto in natura é altamente nutritivo e contêm $85 \%$ de água, $10 \%$ de carboidratos, elevado conteúdo de minerais, vitaminas do complexo B e A e cálcio, além de ser fonte de compostos funcionais, como ácido elágico e antocianinas (ANTUNES; FILHO, 2002; MORENOALVAREZ et al., 2002).

Em razão da produção concentrada nos meses de novembro à fevereiro e a rápida perda de qualidade pós-colheita, há uma grande limitação quanto ao fornecimento dos frutos ao mercado 
in natura no Brasil. Uma alternativa viável para o aproveitamento econômico desses frutos é a industrialização, pois estes podem ser congelados, enlatados, processados na forma de polpa para utilização em produtos lácteos (como matéria prima ou aditivo de cor e sabor), ou na forma de sucos e geleias (ANTUNES, 2002).

Outro diferencial que vêm chamando a atenção, principalmente dos consumidores, e que tem aumentando a demanda pela fruta, é seu conteúdo de compostos funcionais, os quais, segundo diversos estudos tanto in vitro quanto in vivo, proporcionam inúmeros benefícios à saúde humana. Destacando-se seus teores de compostos antociânicos e polifenóis com elevada capacidade antioxidante e que tem sido associados a redução do risco de desenvolvimento de tumores, entre eles o câncer de esôfago (WANG et al., 2009).

\subsubsection{Cranberry}

O cranberry (Vaccinum macrocarpon) (Figura 3) é uma fruta nativa da América do Norte, apresenta em sua composição antocianidinas, flavonoides, proantocianidinas, taninos condensados e ácidos fenólicos, estes componentes podem impedir a adesão de certas bactérias, incluindo a Escherichia coli, associada às infecções do trato urinário. Pesquisas científicas recentes também demonstram que o cranberry contém quantidades significativas de antioxidantes e outros fitonutrientes com o potencial de impedir danos oxidativos, deste modo, protege o organismo contra doenças cardiovasculares e câncer (KERR, 1999).

Essa fruta tem coloração vermelha, de sabor azedo, cultivada em alguns países da América do Norte. Estudos experimentais demonstraram, in vitro, que preparados de cranberry estiveram associados a diminuição significativa da adesão bacteriana tecidual de cepas de Escherichia coli e de outros patógenos comuns ao trato urinário inferior.

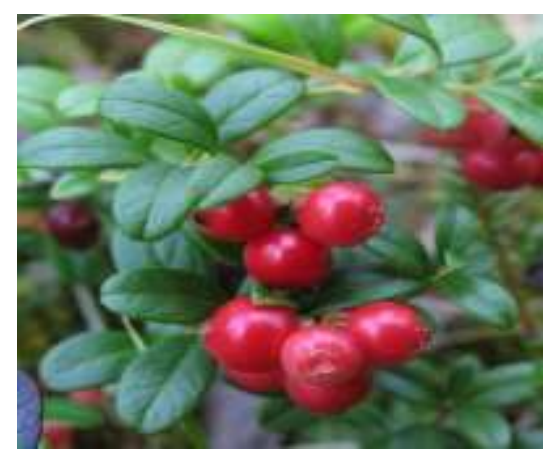

Figura 3: Frutos de cranberry (Vaccinum macrocarpon) Fonte: Google imagens

Em estudo randomizado, envolvendo 137 mulheres com idade superior a 45 anos e episódios recorrentes de ITU (dois ou mais episódios de ITU no último ano), a utilização de cápsulas de cranberry foi tão eficaz quanto a antibioticoprofilaxia com trimetoprima por seis meses, na prevenção de recorrências. 
Análises laboratoriais, estudos observacionais e alguns ensaios randomizados pequenos não controlados sugerem que a ingestão regular de suco de cranberry diminui o risco de problemas do trato urinário (SCHMIDT; SOBOTA, 1988; OFEK et al., 1991; STOTHERS, 2002; FERREIRA et al., 2009).

\subsubsection{Morango}

O morangueiro (Figura 4) é uma planta perene, rasteira, herbácea pertencente à família Rosácea e do gênero fragaria (GOMES, 2007).

De acordo com Chitarra \& Chitarra (2005), a parte comestível é o morango (Fragaria vesca), que é um pseudofruto não climatérico de coloração vermelho brilhante, odor envolvente, textura e sabor levemente acidificado (HENRIQUE; CEREDA, 1999).

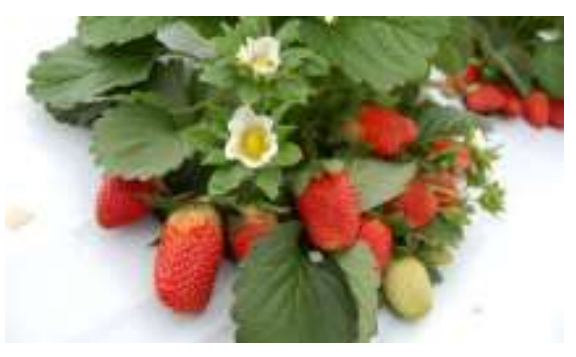

Figura 4: Morango (Fragaria vesca) Fonte: Google imagens

O morango é rico em vitamina C, uma vitamina hidrossolúvel de extrema importância para o organismo humano e encontrada em frutos cítricos. Desempenha um papel fundamental no desenvolvimento e regeneração dos músculos, pele, dentes e ossos, na formação do colágeno, na regulação da temperatura corporal, na produção de diversos hormônios e no metabolismo em geral (ANDRADE et al., 2002).

O seu poder antioxidante deve-se ao grupo diol (- $\mathrm{COH}-\mathrm{COH}-$ ), o qual pode oxidar-se e formar o ácido desidroascórbico (SILVA \& MURA, 2007), e a enzima envolvida nesse processo é o ácido ascórbico oxidase (BRAVERMAN, 1967).

O consumo do morango está ligado não somente à forma e ao tamanho, mas também ao aroma e à cor. A cor vermelha é um importante componente na aparência de morangos, sendo um atrativo aos consumidores. Essa coloração intensa se deve às antocianinas presentes nos frutos, principalmente na epiderme e aquênios (BORDIGNON et al., 2009).

\subsubsection{Uva roxa}

As uvas (Vitis vinifera L.) (Figura 5) são consideradas uma das maiores fontes de compostos fenólicos quando comparadas a outras frutas e vegetais (MAXCHEIX; FLEURIET; BILLOT, 1990). 
Os compostos fenólicos das uvas podem ser classificados em flavonóides e não-flavonóides. Do primeiro grupo fazem parte os flavanóis (catequina, epicatequina e epigalocatequina), flavonóis (caempferol, quercetina e miricetina) e antocianinas, e ao segundo grupo pertencem os ácidos fenólicos, hidroxibenzóicos e hidroxicinâmicos (CABRITA; RICARDO-DA-SILVA; LAUREANO, 2003).

Os compostos fenólicos presentes em produtos derivados da uva como suco de uva e vinhos, em especial vinho tinto, apresentam atividade antioxidante que combate a radicais livres. Estudos direcionados a avaliar a atividade antioxidante e quantificar compostos fenólicos, comprovaram que o vinho tinto apresentou maiores teores de compostos fenólicos e melhor atividade antioxidantes (ISHIMOTO, 2003).

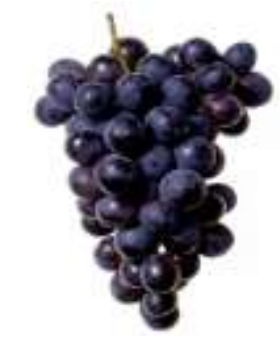

Figura 5: Uvas Roxas (Vitis vinifera L.)

Fonte: Google Imagens

\subsection{Constituintes químicos}

Os constituintes químicos são fundamentais à sobrevivência dos animais. São adquiridos a partir da alimentação, absorvidos no aparelho digestivo e degradados para formarem outras substâncias essenciais para o organismo. São divididos em macronutrientes e micronutrientes. Os macronutrientes (carboidratos, lipídeos e proteínas) são os que formam o corpo da dieta e fornecem energia. Os micronutrientes são as vitaminas e vários sais minerais, que complementam a alimentação. Outras substâncias da dieta também são importantes para o organismo, como as fibras e as substâncias bioativas (ALVES, 2011).

As substâncias bioativas podem ser definidas como nutrientes e/ou não com ação metabólica ou fisiológica específica. Algumas dessas substâncias já possuem alegações aprovadas, como os ácidos fenólicos, ácidos graxos monoinsaturados, cafeína, estearato de sódio, fibras, fitoesteróis e outros. Estas substâncias podem exercer seus efeitos agindo como antioxidantes, bloqueando a atividade de toxinas virais ou bacterianas, inibindo a absorção do colesterol, diminuindo a agregação plaquetária, ou destruindo bactérias gastrintestinais nocivas (PENNINGTON, 2002; ALVES, 2011).

\subsubsection{Compostos fenólicos}

Os compostos fenólicos são substâncias amplamente distribuídas na natureza, mais de 8000 compostos fenólicos já foram detectados em plantas. Esse grande e complexo grupo faz parte dos constituintes de uma variedade de vegetais, frutas e produtos industrializados. Podem ser pigmentos que dão a aparência colorida aos alimentos ou produtos do metabolismo secundário. Normalmente derivado de reações de defesa das plantas contra agressões do ambiente. Esses 
compostos agem como antioxidantes, não somente pela sua habilidade em doar hidrogênio ou elétrons, mas também em virtude de seus radicais intermediários estáveis, que impedem a oxidação de vários ingredientes do alimento, particularmente de lipídios (BRAND-WILLIAMS; CUVELIER; BERSET, 1995).

Estudos realizados com os compostos fenólicos demonstram sua capacidade antioxidantes, assim como seu possível efeito na prevenção de diversas enfermidades cardiovasculares, cancerígenas e neurológicas (HARBORNE; WILLIAMS, 2000; SÁNCHEZ-MORENO, 2002).

De maneira geral, a ação benéfica dos compostos fenólicos na saúde humana vem sendo relacionada com a sua atividade anti-inflamatória e com a atividade que impede, não só a aglomeração das plaquetas sanguíneas, mas também a ação de radicais livres no organismo. Uma vez que protege moléculas como o DNA, podem vir a abortar alguns processos carcinogênicos. (HARBORNE; WILLIAMS, 2000; SÁNCHEZ-MORENO, 2002).

\subsubsection{Antioxidantes}

Antioxidante é qualquer substância que, presente em baixa concentração comparada à do substrato oxidável, reduz significativamente ou previne a oxidação destas substâncias (BECKER; NISSEN; SKIBSTED, 2004).

A oxidação nos sistemas biológicos ocorre devido à ação desses radicais livres no organismo. A ingestão em quantidades adequadas de frutas e vegetais ricos em antioxidantes contribui para equilibrar o estado de oxirredução orgânico, impedindo a proliferação de danos por oxidação e suas consequências que incluem incidência de doença cardiovascular, certos tipos de câncer e doenças degenerativas (BARRETT, 2007).

Os antioxidantes naturais presentes na dieta aumentam a resistência aos danos provocados pela oxidação, que gera os radicais livres ou ERO, apresentando um impacto significativo para a saúde humana (TERMENTZI; 2006).

Várias fontes de antioxidantes naturais são conhecidas e algumas são amplamente encontradas no reino vegetal. Esses compostos quando adicionados a produtos alimentares, podem aumentar a vida útil por retardar processos de deteriorações durante o processamento e armazenamento, como a peroxidação lipídica (SIES; STAHL, 1995). Entre as fontes de antioxidantes naturais destacam-se as frutas, que apresentam expressiva diversidade e quantidade de compostos.

Encontra-se atualmente uma série de relatórios que expressam a atividade antioxidante das frutas vermelhas determinada por vários métodos, tais como capacidade de absorção de radical oxigênio ou capacidade de seqüestrar o radical DPPH indicando que frutas como chokeberry, elderberry e groselha preta possuem forte atividade antioxidante (BENVENUTI et al., 2004).

Os antioxidantes podem ser classificados em primários e secundários. Os primários atuam interrompendo a cadeia da reação através da doação de elétrons ou hidrogênio aos radicais livres, convertendo-os em produtos termodinamicamente estáveis e/ ou reagindo com os radicais livres, 
formando o complexo lipídio-antioxidante que pode reagir com outro radical livre. Os antioxidantes secundários atuam retardando a etapa de iniciação da autoxidação, por diferentes mecanismos que incluem complexação de metais, sequestro de oxigênio, decomposição de hidro peróxidos para formar espécie não radical, absorção da radiação ultravioleta ou desativação de oxigênio (KÄHKÖNEN et al, 1999).

\subsubsection{Antocianinas}

As antocianinas são compostos da família dos flavonoides e constituem grupo de pigmentos responsáveis por grande parte das cores em flores, frutas, folhas, caules e raízes de plantas. Esses pigmentos conferem diferentes tonalidades de cor, oscilando entre vermelho, laranja e roxo, de acordo com condições intrínsecas, como o pH, encontradas nos vegetais (BROUILLARD, 1982).

Segundo Kong, (2003) são poucas as fontes de antocianinas comercialmente utilizadas, apesar de existirem aproximadamente 400 tipos de antocianinas presentes em diversas plantas como uva, cereja, morango, amora, maçã, azeitona, figo, marmelo, jabuticaba, cacau, repolho roxo, rabanete, berinjela, feijão, poucas apresentam-se como fonte comercial desse pigmento.

O consumo regular de antocianinas e outros polifenóis estão associados à redução dos riscos de doenças crônicas. As antocianinas constituem uma ampla gama de atividades biológicas, incluindo antioxidante, anti-inflamatória, anticancerígeno e atividades quimiopreventivas. Além disso, estes pigmentos podem reduzir o risco de doença cardíaca coronária, através da inibição da agregação de plaquetas (CAVALCANTI; VEGGI; MEIRELES; 2011).

\subsection{Fibras Alimentares}

As fibras são consideradas ingredientes funcionais uma vez que seu consumo tem um papel importante na prevenção de alguns males como constipação, diabetes, obesidade e doenças cardiovasculares (THEBAUDIN et al., 1997).

São componentes de plantas ou carboidratos análogos que são resistentes à digestão e absorção no intestino delgado humano. Uma dieta rica em fibras traz benefícios à manutenção da saúde, redução de riscos e tratamento de várias doenças (SAAD, 2006).

As fibras estão incluídas na categoria dos carboidratos e podem ser classificadas como solúveis, insolúveis ou mistas, podendo ainda ser fermentáveis ou não fermentáveis. Uma descrição recente sugerida pela American Association of Cereal Chemists (2010), cita que fibra dietética é definida como polímeros de hidratos de carbono com mais de uma polimerização de três graus que não são nem digeridos nem absorvidos no intestino delgado.

Lattimer e Haub (2010) explicam que na forma mais simples, hidratos de carbono podem ser separados em dois grupos básicos com base na sua digestibilidade no trato gastro intestinal. 0 primeiro grupo (amido, açúcares simples, e frutanos) é facilmente hidrolisado por reações enzimáticas e absorvido no intestino delgado. O segundo grupo (celulose, fibras, hemicelulose, pectina e beta-glucanas) são resistentes à digestão no intestino delgado e requerem fermentação 
bacteriana localizado no intestino grosso. Estes compostos podem ser referidos como carboidratos complexos, polissacarídeos não-amido (NSP) ou carboidratos estruturais.

Uma característica fundamental da fibra solúvel é sua capacidade de ser metabolizada por bactérias. As fibras insolúveis também ajudam na prevenção de algumas doenças, como a constipação intestinal ou "prisão de ventre" e o câncer de colo e reto. Atuam principalmente no trânsito intestinal, acelerando o movimento do bolo fecal através do intestino (RODRíGUEZ et al., 2003).

\subsubsection{Polidextrose}

A polidextrose é um polissacarídeo sintetizado pela polimerização randômica da glicose (STUMM; BATLES, 1997) e pode ser considerado como alimento funcional, pois é parcialmente fermentado no intestino grosso, mas não é digerido nem absorvido no intestino delgado e, em sua maior parte, é excretado nas fezes (PFIZER, 1978). Além disso, este polímero é extremamente estável, incolor e não apresenta sabor residual, sendo também altamente estável dentro de uma faixa ampla de $\mathrm{pH}$, temperatura, condições de processamento e estocagem (JIE et al., 2000). É tolerada uma média de 90g por dia, sem efeitos laxativos (FAKHOUR et al., 2005). Segundo Jie et al. (2000), a polidextrose pode ser também considerada como pré-biótico, pois estimula o crescimento de lactobacilos e bifidobactérias e a fermentação contínua ao longo do cólon. Esta última promove a redução do $\mathrm{pH}$ fecal e a produção de ácidos graxos de cadeia curta, destacandose o butirato, que pode reduzir riscos de câncer.

Alguns autores relataram que a utilização da polidextrose diminuiu as calorias de sorvetes em $50 \%$, de produtos assados em $33 \%$ e de sobremesas de $50-70 \%$ em relação aos produtos tradicionais (SINGHAL; REKHA; GUPTA; KULKARNI, 1991).

A polidextrose não é hidrolisada no intestino após administração oral (CRAIG et al., 1998). Ele é fermentado no intestino grosso produzindo ácidos graxos de cadeia curta e $\mathrm{CO} 2$, outra parte é excretada nas fezes (YSHIOKA; SHIMOMURA; SUZUKI, 1994 ). Polidextrose aumenta o volume da massa fecal, reduz o tempo de trânsito intestinal, amolece as fezes e reduz o pH fecal. A fermentação leva a simbiótica do crescimento de membros favoráveis da microbiota, e suprime a produção de metabolites carcinogênicos (ZHONG et al., 2000).

\subsubsection{Sucralose}

Diversos estudos estão sendo realizados sobre produtos preparados com edulcorantes (substitutos do açúcar) para a melhoria do paladar (CALIL, 1999). Os produtos mais estudados são os refrigerantes preparados à base de edulcorantes, isso porque conferem um paladar residual final não agradável (aftertaste). Essa condição é agravada devido ao sabor metálico ou amargo de alguns edulcorantes, característica marcante dessa linha de refrigerantes (CÂNDIDO; CAMPOS, 1996).

A sucralose é uma substância que apresenta um grande potencial para melhoria do paladar, uma vez que é derivada do próprio açúcar, tem sabor agradável, apresenta um baixo residual final, 
e pode ser ingerida pelos diabéticos pelo fato de não ser reconhecida pelo organismo como um carboidrato.

A sucralose, quimicamente denominada 1,6-dicloro-didesoxi- $\beta$-Dfrutofuranosil-4-cloro-4deoxi- $\alpha$-D-galactopiranosídeo, é obtida pela cloração da sacarose de forma seletiva nas posições $4,1^{\prime}$ e $6^{\prime}$ da molécula do açúcar. É seiscentas vezes mais doce que a sacarose em solução a $5 \%$ e isenta de calorias (CÂNDIDO e CAMPOS, 1996).

A ingestão diária admissível (IDA) para a sucralose foi fixada em 15mg por quilograma de peso corpóreo (ZINK, 2000).

A sucralose teve seu uso aprovado no Brasil pela Portaria no 318 do Ministério da Saúde (BRASIL, 1995). A sucralose é considerada edulcorante de alta qualidade e elevada potência, com extraordinária estabilidade e boas características físico-químicas (solubilidade em água e etanol), o que permite sua aplicação em vários alimentos e bebidas. Além disso, após inúmeros estudos clínicos, foi considerada segura para consumo humano (MILLER, 1991).

\subsection{Refrigerante}

Segundo a Associação Brasileira das Indústrias de Refrigerantes e Bebidas não Alcóolicas $(A B I R)$, o refrigerante é uma bebida industrializada, não alcoólica, carbonatada, adicionada de aromas, com alto poder refrescante. Uma lata de refrigerante do tipo cola contém cerca de sete a nove colheres de sopa de açúcar (WILLETT, 2001). Pode-se dizer que os refrigerantes fornecem calorias vazias, sem nenhum tipo de nutriente, sem nenhum valor nutritivo (SWEETMAN; WARDLE; COOKE, 2008).

Refrigerante é a bebida gaseificada, obtida pela dissolução, em água potável, de suco ou extrato vegetal de sua origem, adicionado de açúcar. O refrigerante deverá ser obrigatoriamente saturado de dióxido de carbono, industrialmente puro (BRASIL, 1999).

Os principais ingredientes na formulação de um refrigerante são: suco de frutas, extrato vegetal, açúcar, água e dióxido de carbono (gás carbônico). No entanto, a aparente simplicidade do produto abriga complexas formulações, manufatura, controle de qualidade, embalagem, tecnologias de inspeção e envase, movimentação de carga, etc., caracterizando-se como um segmento altamente interdisciplinar e dinâmico, inserido em uma realidade de mercado enormemente exigente e competitiva (VENTURINI FILHO et al., 2005).

O consumo de refrigerantes por crianças e adolescentes é influenciado, principalmente, pelo sabor do produto, além do consumo pelos pais, que se torna modelo para os jovens (GRIMM; HARNACK; STORY, 2004).

De acordo com o MAPA (Ministerio da Agicultura Pecuária e Abastecimento), os refrigerantes de laranja, tangerina e uva deverão conter, obrigatoriamente, no mínimo dez por cento em volume do respectivo suco na sua concentração natural. 


\section{METODOLOGIA}

O experimento foi desenvolvido nos Laboratórios de Físico-química, Microbiologia, Análise Sensorial e no Setor de Processamento de Frutos e Hortaliças, do Instituto Federal de Minas Gerais Campus Bambuí no período de Fevereiro à dezembro de 2014.

\subsection{Obtenção das amostras}

As frutas in natura: amora-preta, morango e uva-roxa foram adquiridas no estabelecimento "Sacolão" situado no município de Bambuí-MG e logo após a aquisição foram selecionadas, lavadas em água corrente, sanitizadas com solução de hipoclorito de sódio (200 mg kg-1) e armazenadas sobre refrigeração para posterior utilização. Já a polpa de cranberry, que estava concentrada à 65 을, foi gentilmente cedida pela empresa Juxx ${ }^{\circledR}$ e a polidextrose cedida pela empresa Tovani ${ }^{\circledR}$.

\subsubsection{Obtenção do xarope de frutas vermelhas}

Foram produzidas três diferentes formulações de xaropes (representados na Tabela 1), distintas entre si quanto à concentração de açúcar e sucralose, sendo denominados como R1 (controle), R2 (light) e R3 (diet).

Tabela 1: Formulações dos xaropes ${ }^{1}$

\begin{tabular}{|c|c|c|c|}
\hline \multirow[b]{2}{*}{ Ingredientes } & \multicolumn{3}{|c|}{ FORMULAÇÕES\% } \\
\hline & $\begin{array}{c}\text { R1 } \\
\text { Controle }\end{array}$ & $\begin{array}{l}\text { R2 } \\
\text { Light }\end{array}$ & $\begin{array}{c}\text { R3 } \\
\text { Diet }\end{array}$ \\
\hline Polpa & 75 & 75 & 75 \\
\hline Açúcar & 22 & 12 & - \\
\hline Polidextrose & 3 & 3 & 3 \\
\hline Sucralose & - & 1,8 & 3,6 \\
\hline Sorbato de potássio & 1 & 1 & 1 \\
\hline Ácido cítrico & 0,5 & 0,5 & 0,5 \\
\hline
\end{tabular}

${ }^{(1)}$ Formulações: R1 (controle), R2 (light) e R3 (diet).

Para a elaboração do xarope foram pesados e adicionados sequencialmente os ingredientes em pó (açúcar, sucralose, polidextrose, ácido cítrico e sorbato de potássio) e misturados em um saco plástico estéril. Em seguida, após as polpas serem devidamente separadas das sementes e cascas, foram adicionadas as polpas de amora-preta, morango, uva-roxa e cranberry em um liquidificador industrial onde foram homogeneizados para a distribuição uniforme dos ingredientes. Posteriormente, a mistura foi pasteurizada à 62,8 으, por 30 min e depois resfriada à 10 ㄷ para eliminação da carga microbiana e obtenção dos xaropes. Após o processamento, o 
xarope foi separado das partículas mais grosseiras com auxílio de uma peneira e encaminhado ao armazenamento para posterior utilização (Figura 1).

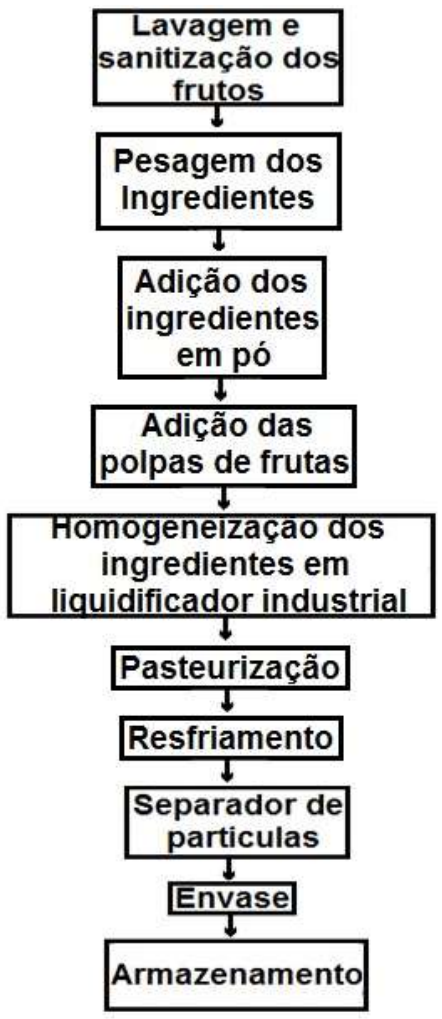

Figura 1: Fluxograma de elaboração do xarope

\subsubsection{Obtenção dos Refrigerantes}

Em um liquidificador industrial foram misturadas concentrações proporcionais de $750 \mathrm{ml}$ de água e $250 \mathrm{~g}$ de xarope, respectivamente para R1, R2 e R3. Após homogeneização, o mix obtido recebeu gás carbônico através do carbonatador SodaStream ${ }^{\circledR}$. O refrigerante obtido foi então armazenado em garrafas de polietileno lacradas e deixado sob refrigeração para posterior utilização.

\subsection{Caracterização Físico-química}

A fração de cinzas foi obtida gravimetricamente, avaliando-se a perda de peso do material submetido ao aquecimento a 550ㄷ em mufla (AOAC, 1997).

A determinação do $\mathrm{pH}$ foi feita mediante o método eletrométrico, utilizando-se um pHmetro digital (IAL, 1985).

Os teores de SST foram obtidos por leitura direta em refratômetro (marca Atago n.1 $0^{\sim} 32^{\circ}$ Brix) e os valores expressos em ${ }^{\circ}$ Brix (PRADO, 2009).

A acidez titulável foi determinada de acordo com a metodologia descrita por Pregnolato e 
Pregnolato (1985).

Para determinação do teor de antocianinas, utilizou-se o método descrito por Giusti; Wrostland (2001) com modificações. O método baseou-se em dois sistemas tampão, o cloreto de potássio $0,025 \mathrm{M}, \mathrm{pH}$ 1,0 e o acetato de sódio $0,4 \mathrm{M}, \mathrm{pH} 4,5$. A diluição consistiu em $20 \mathrm{~g}$ de amostra adicionadas a $32 \mathrm{~mL}$ de etanol, sendo esta solução filtrada. Da solução filtrada, alíquotas de 0,3 mL foram retiradas e adicionadas a $2,7 \mathrm{~mL}$ das soluções tampão, separadamente. As amostras foram então analisadas a 510 e $700 \mathrm{~nm}$ em espectrofotômetro.

\subsection{Caracterização Microbiológica}

Antes de serem abertas, as embalagens foram limpas na área externa com etanol $70 \%$ para remoção dos contaminantes presentes. A partir das diluições obtidas, foram realizadas análises de Coliformes totais e à 45으 segundo as técnicas preconizadas em BRASIL (1993).

Para análise de Staphylococcus aureus, foi inoculado $0,1 \mathrm{~mL}$ de cada diluição na superfície de placas de Agar Baird-Parker (BP). As placas foram Incubadas invertidas a 370 C por 48h. A metodologia foi realizada conforme descrito em BRASIL (2003).

\subsection{Análise Sensorial}

Para a Avaliação Sensorial foram utilizados 50 provadores não treinados e foi aplicado o teste de aceitabilidade utilizando-se escala hedônica estruturada de nove pontos variando de " 1 " (desgostei extremamente) à " 9 " (gostei extremamente). Os atributos avaliados foram: aparência, sabor e aspecto global. Os provadores também foram questionados quanto a intenção de compra do produto e utilizouse escala hedônica de 5 pontos, variando de 5 "certamente compraria" e 1 "certamente não compraria" (ABNT, 1998).

\subsection{Análise Estatística}

Os dados obtidos foram analisados estatisticamente por análise de variância (ANOVA) pelo programa Sisvar e por teste de médias de Tukey. As diferenças foram consideradas.

\section{RESULTADOS E DISCUSSÃO}

\subsection{Análises físico-químicas}

Os teores de potencial hidrogeniônico $(\mathrm{pH})$, sólidos solúveis totais (SST), acidez total titulável (ATT), cinzas e antocianinas dos refrigerantes estão apresentados na Tabela 2. 
Tabela 2: Valores de $\mathrm{pH},{ }^{\circ} \mathrm{Brix}$ (SST), Acidez, Cinzas e Antocianinas dos refrigerantes ${ }^{(1)}$

\begin{tabular}{|c|c|c|c|c|c|c|}
\hline Formulações ${ }^{(2)}$ & $\begin{array}{l}\text { oBrix }^{(3)} \\
\text { (SST) }\end{array}$ & $\mathrm{pH}$ & $\begin{array}{l}\text { Acidez }^{(4)} \\
\text { (ATT) }\end{array}$ & $\begin{array}{l}\text { Cinzas } \\
\text { (g/100g) }\end{array}$ & $\begin{array}{l}\text { Umidade } \\
\text { (g/100g) }\end{array}$ & $\begin{array}{l}\text { Antocianin } \\
\text { as } \\
\text { (mg/100g) }\end{array}$ \\
\hline R1 & $35 \pm 0.06^{a}$ & $2,27 \pm 0.04^{a}$ & $5,24 \pm 0.05^{a}$ & $0,6 \pm 0.03^{a}$ & $9,8 \pm 0.04^{b}$ & $39 \pm 0.03^{a}$ \\
\hline $\mathrm{R} 2$ & $25 \pm 0.25^{b}$ & $2,22 \pm 0.06^{a}$ & $5,15 \pm 0.07^{a}$ & $0,3 \pm 0.012^{b}$ & $10.1 \pm 0.13^{b}$ & $41 \pm 0.18^{b}$ \\
\hline R3 & $12 \pm 0.05^{C}$ & $2,17 \pm 0.13^{b}$ & $5,05 \pm 0.16^{b}$ & $0,2 \pm 0.09^{b}$ & $10.1 \pm 0.24^{b}$ & $41 \pm 0.09^{b}$ \\
\hline $\begin{array}{l}\text { Valores médio } \\
\text { (1)Média } \pm \text { desvio } \\
\text { (2)Formulações:R } \\
\text { (3)Expresso em }{ }^{\circ} \mathrm{B} \\
\text { (4) Expresso em \% }\end{array}$ & $\begin{array}{l}\quad \text { com le } \\
\text { adrão. } \\
\text { (controle),R2 } \\
\text {-ix } \\
\text { de ácido cítric }\end{array}$ & $\begin{array}{l}\text { as distintas } \\
h t) \text { eR3(diet). }\end{array}$ & na mesma & coluna $\quad d$ & m entre & $(P<0,05)$ \\
\hline
\end{tabular}

$\mathrm{O} \mathrm{pH}$ dos refrigerantes analisados variaram de 2,27; 2,22 e 2,17 para R1, R2 e R3 respectivamente e a única amostra que se diferenciou estatisticamente $(p<0,05)$ foi R3 apresentando o menor resultado. Prado (2013) ao elaborar um refrigerante de laranja encontrou valores de $\mathrm{pH}$ que variaram na faixa de 3,52 à 3,59, mostrando-se menos ácidos que os encontrados nesta pesquisa. Provavelmente as frutas vermelhas adicionadas influenciaram para a queda do $\mathrm{pH}$ pois são frutas ácidas e ricas em componentes antioxidantes.

No que diz respeito à análise de SST, representado por @Brix, os valores encontrados foram de 35, 25 e 12 Brix para R1, R2 e R3 respectivamente. Todas as formulações apresentaram diferença significativa $(p<0,05)$ e expressaram coerência com os teores de sólidos solúveis adicionados. A presença de açúcar nas formulações R2 e R3 (elaboradas com ausência parcial e total da sacarose) está relacionada com a adição de outras fontes açucaradas como as polpas de frutas vermelhas e a polidextrose que também apresentam sólidos solúveis em suas composições. É importante destacar que um elevado teor de Brix pode influenciar na aceitação do produto, pois está diretamente relacionado com o sabor doce. Entretanto, o mercado necessita de produtos que tenham reduzidos teores de açúcar mais que são igualmente aceitos sensorialmente.

Já a acidez total titulável dos refrigerantes é um parâmetro influenciado pela quantidade de ácido cítrico utilizado (que resulta no aumento da vida útil dos produtos) e tendo em vista que as polpas das frutas escolhidas também apresentam ácidos em sua composição (HIRSCH et al., 2012; CARVALHO et al., 2012; FERREIRA-MARÇAL et al., 2013), os refrigerantes expressaram coerência pois apresentaram elevada acidez. Mais uma vez, a única formulação que se diferenciou $(p<0,05)$ foi R3 se enquadrando como a mais ácida.

Os teores de cinzas encontrados foram de 0,6; 0,3; e 0,2 g/100g para R1, R2 e R3 respectivamente. Vale ressaltar, que as amostras R2 e R3 se diferenciaram estatisticamente $(p<0,05)$ de R1.Provavelmente a diferença está relacionada ao teor de sólidos adicionados, pois R1 foi a única formulação em que não houve adição ou substituição de sucralose. Mesmo sendo adicionados $75 \%$ de polpa de frutas vermelhas, os teores de cinzas encontrados estão abaixo do desejado. Provavelmente ocorreu alguma perda durante a realização da análise, pois se sabe que algumas substâncias inorgânicas podem sofrer volatilização durante a secagem ou podem sofrer interação com algum componente da amostra reduzindo os seus teores. 
Os teores de antocianinas encontrados nos refrigerantes foram de 39; 41; e $41 \mathrm{mg} / 100 \mathrm{~g}$ para R1, R2 e R3 respectivamente. Observa-se uma pequena perda de antocianina em R1 e uma explicação pode ser a própria concentração das polpas de frutas vermelhas, pois, segundo Wang \& $\mathrm{Xu}$ (2007), que estudaram a estabilidade das antocianinas em suco concentrado de amora e comparou com o suco integral, o suco concentrado é mais susceptível à degradação das antocianinas devido à proximidade entre moléculas reativas (como oxigênio), acelerando a velocidade de ocorrência das reações de degradação. Este fenômeno também foi relatado por Monteiro (2011), que estudaram a estabilidade de suco concentrado e não concentrado de amorapreta e também verificaram queda nas amostras concentradas.

\subsection{Análises Microbiológicas}

Os resultados das análises microbiológicas para Coliformes Totais, à 45ํㅡ e Staphylococcus aureus, estão apresentados na Tabela 3. Os valores encontrados situam-se dentro dos limites propostos pela legislação brasileira vigente, pois a ANVISA estabelece como tolerância de microrganismos para preparo de bebidas refrigerantes, o valor mínimo para contagem de coliformes à $45 \mathrm{o} \mathrm{C} / \mathrm{g}$ de $10 \mathrm{UFC} / \mathrm{ml}$. Já a contagem de Staphylococcus aureus não é exigida pela Resolução - RDC $n^{\circ} 12$ de 02/01/2001 em refrigerantes e os valores obtidos estão abaixo dos encontrados por Prado (2013).

Tabela 3: Resultados das análises microbiológicas

\begin{tabular}{cccc}
\hline Formulações ${ }^{(1)}$ & $\begin{array}{c}\text { Coliformes Totais } \\
\mathrm{NMP} / \mathrm{g}\end{array}$ & $\begin{array}{c}\text { Coliformes à } 45^{\circ} \\
\mathrm{NMP} / \mathrm{g}\end{array}$ & $\begin{array}{c}\text { Staphylococcus aureus } \\
\mathrm{UFC} / \mathrm{ml}\end{array}$ \\
\hline R1 & $1 \times 10^{2}$ & $<0,3$ & $<0,3$ \\
R2 & $1,5 \times 10^{2}$ & $<0,3$ & $<0,3$ \\
R3 & $4 \times 10^{2}$ & $<0,3$ & $<0,3$ \\
\hline
\end{tabular}

(1) Formulações: R1 (controle), R2 (light) e R3 (diet).

Diante dos resultados, a qualidade microbiológica dos refrigerantes indicou que as condições higiênicas - sanitárias do processamento térmico do xarope, o emprego de matéria-prima de qualidade, condições adequadas de manuseio e a presença dos conservantes sorbato de potássio e ácido cítrico, bem como a carbonatação, foram eficientes para a conservação do produto. Sendo assim, tais resultados são satisfatórios, posto que atendem aos requisitos mínimos de qualidade para o consumo humano. Desta forma, os refrigerantes estão em conformidade com os padrões estabelecidos pela ANVISA (BRASIL, 2001).

\subsection{Análise Sensorial}

Dentre os atributos sensoriais avaliados (aparência, sabor e aspecto global), com exceção da aparência da formulação R3, todos as formulações receberam notas igual ou acima de 7, demonstrando que os provadores gostaram dos refrigerantes desenvolvidos (Tabela 4). 
Tabela 4: Atributos sensoriais e intenção de compra dos refrigerantes (1)

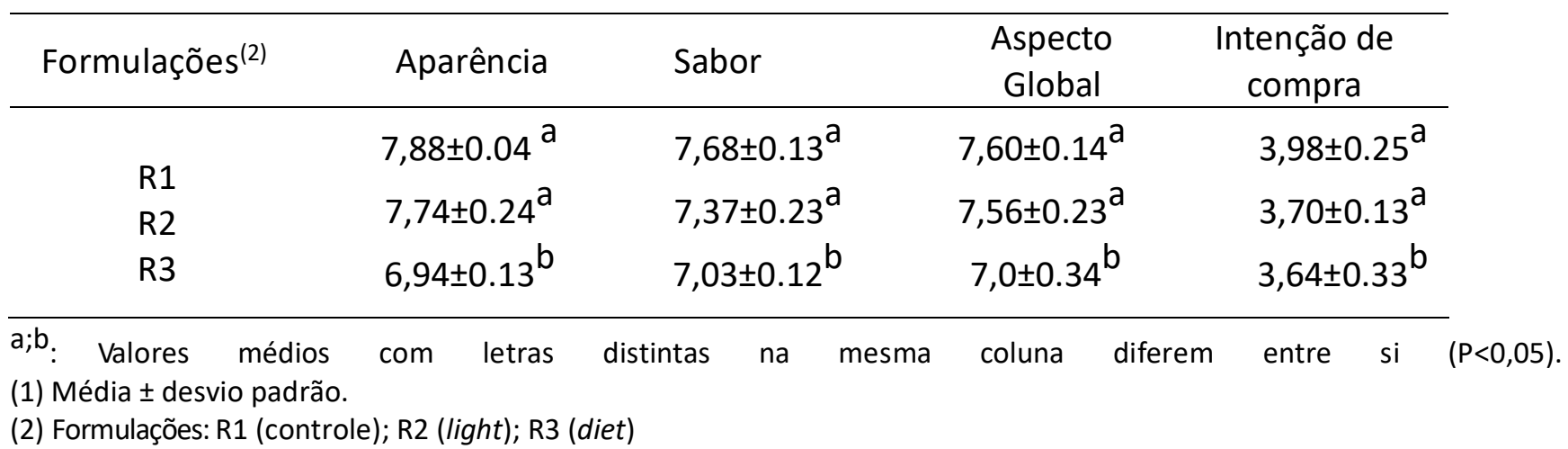

O atributo que mais se destacou foi a aparência da formulação R1 que apresentou nota de 7,8 e que estatisticamente não apresentou diferença $(p<0,05)$ de R2. A ausência do açúcar em R3 provavelmente contribuiu para a redução da sua nota, pois se sabe que este ingrediente quando em contato com o calor promove a caramelização o que contribui para uma melhor aparência dos produtos. Vale destacar que a primeira impressão que se tem de um alimento é geralmente visual, sendo que a aparência é um dos aspectos considerados fundamentais na qualidade e aceitação do produto.

Quando avaliado o atributo sabor, detectou-se mais uma vez que R1 e R2 não apresentaram diferença estatística $(p<0,05)$ se diferenciando de R3. As pessoas de modo geral ainda dão preferência para os produtos que apresentam o conteúdo integral de açúcar e isso faz com que aqueles produtos que não o apresentam tenham uma queda na aceitação. Por outro lado, é crescente o número de pessoas que enfrentam problemas com o excesso de açúcar no sangue e desenvolvem diabetes. Este fato impulsiona o desenvolvimento de produtos que sejam mais saudáveis e que contenham em sua formulação ingredientes que substituem os açúcares e a exemplo cita-se a sucralose, que foi usada neste trabalho.

Os resultados para Aspecto Global também mostrou que R3 se diferenciou estatisticamente $(p<0,05)$ das demais formulações. Esses resultados mostram que são necessários futuros estudos a fim de evitar diferenciação das formulações quando são reduzidos os teores de açúcar. Os valores obtidos mostram que a pesquisa encontra-se no caminho correto pois a ausência parcial do açúcar (detectado em R2) não apresentou nenhuma diferença estatística $(p<0,05)$ para aparência, sabor e aspecto global da formulação com o conteúdo total de açúcar (R1).

Em trabalho realizado por Prado (2013), foram desenvolvidos refrigerantes de laranja com isolado proteico de soro de leite e todos os atributos sensoriais analisados receberam a média superior a 7,0, situando-se entre os termos hedônicos "gostei moderadamente" e "gostei muito", exceto o atributo sabor após 45 dias de armazenamento.

Finalmente, quando questionados sobre a intenção de compra dos produtos em questão, observa-se que os refrigerantes apresentaram notas de 3,98; 3,70 e 3,64 para as formulações R1, R2 e R3 respectivamente e essas notas se enquadram no atributo "talvez comprasse/talvez não comprasse". Esses resultados representam que os consumidores aceitaram os produtos mais ainda não estão 
seguros quanto a compra dos mesmos. Um fato que pode fortalecer a decisão na hora da compra, é a conscientização da qualidade nutricional que os mesmos podem oferecer, entretanto, é necessário um maior investimento em campanhas governamentais, uma vez que a polidextrose é rica em fibras alimentares e pode prevenir o surgimento de doenças, segundo pesquisas científicas. Além do mais, as frutas vermelhas colaboram para o enriquecimento bioativo dos refrigerantes desenvolvidos e colaboram para a descaracterização de um produto conhecido como maléfico para a sociedade. Espera-se "quebrar o tabu" que a ingestão de refrigerante sempre é algo ruim e que irá prejudicar a saúde dos consumidores. Este trabalho mostra que formulações convencionais podem ser modificadas positivamente e assim, contribuir para a redução de doenças e consumo consciente de produtos artificiais. Entretanto, são necessárias novas pesquisas para verificar o efeito in vivo destes produtos e assim, verificar como os mesmos se comportam no organismo humano.

\section{CONCLUSÃO}

Nas condições experimentais da presente pesquisa, os resultados obtidos permitiram concluir que os refrigerantes:

* Podem ser considerados uma importante fonte nutricional e receber alegação de funcional segundo a Legislação por conter $3 \mathrm{~g} / 100 \mathrm{~g}$ de polidextrose como produto enriquecido com fibras alimentares;

* Apresentaram também elevados teores de acidez e baixo pH;

* Obtiveram teores elevados de antocianinas indicando que podem ser utilizados na prevenção de doenças crônico-degenerativas, entretanto são necessárias pesquisas in vivo;

* Encontram-se de acordo com os padrões microbiológicos da legislação vigente;

* Possuíram aceitação sensorial satisfatória para os atributos aparência, sabor e aspecto global indicando a viabilidade comercial das formulações R1 e R2 que não se diferenciaram, mesmo apresentando teores diferentes de açúcar.

\section{REFERÊNCIAS BIBLIOGRÁFICAS}

ALVES, A. P. C. (2011). Casca de jabuticaba (Plinia jaboticaba (Vell.) Berg): processo de secagem e uso como aditivo em iogurte / Ana Paula de Carvalho Alves. - Lavras: UFLA. 90 p. : il.

AMERICAN ASSOCIATION OF CEREAL CHEMISTS. (2010). Adopts oat bran definition. Disponível em: <http://www.aaccnet.org/news/pdfs/OatBran.pdf>. Acesso em: 12 jun. 2014.

ANDRADE, R. S. G. de; DINIZ, M. C. T.; NEVES, E. A. ; NÓBREGA, J.A. (2002). Determinação e distribuição de ácido ascórbico em três frutos tropicais. Eclética Química, São Paulo, v.27, n. especial. 
ANJO, D. F. C. (2004). Alimentos funcionais em angiologia e cirurgia vascular. J Vasc Br 2004; Vol. 3, №2: 145-154.Sociedade Brasileira de Angiologia e Cirurgia Vascular.

ANTUNES, L. E. C. (1999). Aspectos fenológicos, propagação e conservação pós-colheita de frutas de amoreira-preta (Rubus spp.) no sul de Minas Gerais. 1999. 129 p. Tese (Doutorado em Agronomia) - Universidade Federal de Lavras, Lavras.

ANTUNES, L. E.C. (2002). Amora-preta: Nova opção de cultivo no Brasil. Ciência Rural, Santa Maria, v. 32 , n. 1, p. 151-158.

ANTUNES, L. E. C.; REGINA, M. A.; DUARTE FILHO, J. (2002). A cultura da amora-preta. Belo Horizonte: EPAMIG. 28p. (EPAMIG. Boletim Técnico, 69).

ASSOCIAÇÃO BRASILEIRA DE NORMAS TÉCNICAS. (1998). NBR 14141: escalas utilizadas em análise sensorial de alimentos e bebidas. Rio de Janeiro. $3 \mathrm{p}$.

ASSOCIATION OF OFFICIAL ANALYTICAL CHEMISTS. (1997). Official methods of analysis of the AOAC International. 16th ed. Gaitherburg.

BARRETT, J. R. (2007). Hyperactive ingredients? Environ Health Perspect, v. 115, p. 578.

BECKER, E.M.; NISSEN, L.R.; SKIBSTED, L.H. 2004. Antioxidant evaluation protocols: food quality or health effects. European Food Research and Technology, Berlin, v. 219, n. 6, p. 561-571.

BENVENUTI, S.; et al. (2004). Polyphenols, anthocyanins, ascorbic acid and radical scavenging activity of Rubus, Ribes, and Aronia. Journal of Food Science, Chicago, v. 69, n. 3, p.164-169.

BORDIGNON JR., Celso Luiz et al. (2009) Influência do pH da solução extrativa no teor de antocianinas em frutos de morango. Ciência e Tecnologia de Alimentos, vol.29, n.1, pp. 183188. ISSN 0101-2061.

BORGES, V. C. (2004). Alimentos funcionais: prebióticos, probióticos, fitoquímicos e simbióticos. In: Waitzberg DL. Nutrição Enteral e Parenteral na Prática Clínica. São Paulo: Atheneu; 2001. Alimentos funcionais em angiologia e cirurgia vascular - Anjo DFC154 J Vasc Br, Vol. 3, №2 .

BRAND-WILLIAMS, W.; CUVELIER, M. E.; BERSET, C. (1995). Use of a free radical method to evaluate antioxidant activity. Lebensmittel-Wissenschaft Technologie, London, v. 28, p. 25-30.

BRASIL. Ministério da Agricultura, Pecuária e Abastecimento. Instrução Normativa $\mathrm{n}$ 62, de 26 de agosto de 2003. (2003). Oficializa os Métodos Analíticos Oficiais para controle de Produtos de Origem Animal e Água. Diário Oficial da República Federativa do Brasil, Brasília, DF, p.6, 05 abr. 2003. Seção 1. Brasília-DF.

BRASIL. MAPA, Ministério da Agricultura e do Abastecimento. Leis, Decretos, etc. Portaria 101, de 11 de agosto de 1993. (1993). O Secretário de Defesa Agropecuária do Ministério da Agricultura e do Abastecimento. RESOLVE: Aprovar e oficializar os métodos analíticos para controle de produtos de origem animal e seus ingredientes - métodos microbiológicos.

BRASIL. Ministério da Saúde. (1995) Secretaria de Vigilância Sanitária. Portaria no 318 de 24 de novembro de 1995. Aprova o uso de sucralose com a função de edulcorante em alimentos e 
bebidas dietéticas. Diário Oficial [da] República Federativa do Brasil, Brasília, n. 227, p.19406, 28 nov.

BRASIL. Portaria n.o 398, de 30 de abril de 1999. Aprova o regulamento técnico que estabelece as diretrizes básicas para análise e comprovação de propriedades funcionais e ou de saúde alegadas em rotulagem de alimentos. Publicada no Diário Oficial da União, Poder Executivo, em 03 de maio de 1999.1 Disponível em: http://elegis.anvisa.gov.br/leisref/public/showAct.php?id=11297\&word=alimentos funcionais. Acesso em: 21 nov. 2014.

BRASIL. Portaria n. 398, de 30 de abril de 1999. Aprova o regulamento técnico que estabelece as diretrizes básicas para análise e comprovação de propriedades funcionais e ou de saúde alegadas em rotulagem de alimentos. Publicada no Diário Oficial da União, Poder Executivo, em 03 de maio de 1999.1 Disponível em: http://elegis.anvisa.gov.br/leisref/public/showAct.php?id=11297\&word=alimentos funcionais. Acesso em: 21 nov. 2014.

BRASIL. Resolução RDC n. 12, de 02 de janeiro de 2001. Aprova o regulamento técnico sobre padrões microbiológicos para alimentos. Diário Oficial da União, Poder Executivo, Brasília, DF, 10 de janeiro de 2001.

BRAVERMEN, J. B. S. (1967). Introduction a la bioquimica de los alimentos. Barcelona: Omega. cap. 14. p 206-241.

BROUILLARD, R. Chemical structure of anthocyanins. In: MARKAKIS, P. Anthocyanins as Food Colors. New York, Academic Press. 1982, p. 1-39.

BROWN, D. The Royal Horticultural Society. New Encyclopedia of Herbs and their Uses. London: Dorling Kindersley, 2002.

CABRITA, M. J.; RICARDO-DA-SILVA, J.; LAUREANO, O. Os compostos polifenólicos das uvas e dos vinhos. In: I SEMINÁRIO INTERNACIONAL DE VITIVINICULTURA. Anais...Ensenada, México, 2003.

CALIL, R. Aditivos nos Alimentos. São Paulo: Impresso do Brasil.1999.

CÂNDIDO, L. M. B. \& CAMPOS, A. M. Alimentos para fins especiais: dietéticos. São Paulo: Ed. Varela, 1996. 423p.

CARVAlHo, S. F. de; FerReiRA, L. V.; PICOLOTTO, C. C. L.; CANTILANO, R. F. F.; ANTUNES, L. D. Caracterização física e química de cultivares de morango de dias neutros. EMBRAPA, 2012. 3p. Disponível em: <http://ainfo.cnptia.embrapa.br/digital/bitstream/item/69922/1/6.pdf>. Acesso em: 12 set. 2014.

CAVALCANTI, R. N.; VEGGI, P. C.; MEIRELES, M. A. A. Supercritical fluid extraction with a modifier of antioxidant compounds from jabuticaba (Myrciaria cauliflora) byproducts: economic viability. Procedia Food Science, v. 1, p. 1672- 1678, 2011.

CHITARRA, M. I. F.; CHITARRA, A. B. (2005). Pós-colheita de frutos e hortaliças: fisiologia e manuseio. Lavras: ESAL/FAEPE. 735p. 
CRAIG, S. A. S.; HOLDEN, J. F.; TROUP, J. P.; AUERBACH, M. H.; FRIER, H. I. (1998). Polydextrose as soluble fiber: physiological and analytical aspects. Am Assoc Cereal Chem; 43(5):84-8.

DE BARCELLOS, M. D., AGUIAR, L. K., FERREIRA, G. C., VIEIRA, L. M. (2009). Willingness to try innovative food products: A comparison between british and brazilian consumers. Brazilian Administration Review, 6(1), Jan-Mar, 50-61.

FAKHOURI, F. M. et al. (2005). Aceitação e intenção de compra de massas alimentícias frescas enriquecidas com extratos vegetais. In: SIMPÓSIO LATINO-AMERICANO DE CIÊNCIA DE ALIMENTOS, SLACA, $6^{\circ}$, Campinas, Anais... Campinas. (CD Rom).

FERREIRA, D. S.; ROSSO, V. V.; MERCADANTE, A. Z. (2010). Compostos bioativos presentes em amora-preta (Rubus spp.). Rev. Bras. Fruticultura, vol.32, n.3, pp. 664-674. ISSN 0100-2945.

FERREIRA-MARÇAL, P. H.; DIAS-SOUZA, M. V.; VILLELA, E. G.; LUZ, L. M.; PEREIRA, M. K.; VALE, C. H. B. do.; RABELO, F. L. A. Qualidade Físico-Química, Microbiológica e Microscópica de Polpas de Frutas Congeladas Comercializadas no Município de Governador Valadares, MG. Rev Nova Científica, Governador Valadares, MG, v.2, n.2, 12p. Disponível em: <http://177.159.202.218:83/index.php/NOVA/article/view/50/32>. Acesso em: 15 out. 2014.

GIUSTI, M.; WROLSTAD, R. E. (2001). Characterization and Measurement of Anthocyanins by UVVisible Spectroscopy. Current Protocols in Food Analytical Chemistry F1.2.1-F1.2.13.

GRIMM, G. C.; HARNACK, L.; STORY, M. (2004). Factors associated with soft drink consumption in school-aged children. J Am Diet Assoc; 104:1244-9.

GOMES, P. (2007). Fruticultura brasileira. 13.ed. São Paulo: Nobel. p.342-348.

HARBORNE, J. B.; WILLIAMS, C. A. (2000). Advances in flavonoid research since 1992. Phytochemistry, New York, v. 52, n. 6, p. 481- 504.

HENRIQUE, C.M. ; CEREDA, M. P. (1999). Utilização de biofilmes na conservação pós- colheita de morango (Fragaria Ananassa Duch) cv IAC Campinas. Ciência e Tecnologia em Alimentos, Campinas,v.19, n.2, p.270-276.

HIRSH, G. E.; FACCO, E. M. P; RODRIGUES, D. B.; VIZZOTO, M.; EMANUELLI, T. (2012). Caracterização físico-química de variedades de amora preta da região sul do Brasil. Ciência Rural. V.42, n.5. Disponível em: http://www.redalyc.org/articulo.oa?id=33122632026. Acesso em: 14 set. 2014.

ISHIMOTO, E. Y. (2003) Atividade antioxidante in vitro em vinhos e sucos de uva. Dissertação de Mestrado. Faculdade de Saúde Pública, Universidade de São Paulo. São Paulo.

INSTITUTO ADOLF LUTZ. (1985). Métodos químicos e físicos para análise de alimentos. 3. ed. São Paulo. $78 \mathrm{p}$.

JIE, Z. et al. (2000). Studies on the effects on the polidextrose intake on physiologic functions on Chinese people. American Journal of Clinical Nutrition, v. 72, n. 6, p. 1503-1509. 
KÄHKÖNEN, M. P.; HOPIA, A.I.; VOURELA, H. J.; RAUHA, J. P.; PIHLAJA, K.; KUJALA, T. S.; HEINONEN, M. (1999). Antioxidant activity of plant extracts containing phenolics compounds. J Agricultural Food Chem; 47(10):3954-62.

KERR, K. G. - The lancet. (1999). Cranberry juice and prevention of recurrent urinary tract infection.

KONG, J. M. (2003) Analysis and biological activities of anthocyanins. Phytochemistry, 64:929-933.

LATTIMER, J. M.; HAUB, M.D. (2010). Effects of dietary fiber and its components on metabolic health. Nutrients, Basel, v. 2, p. 1266-1289.

MAXCHEIX, J. J.; FLEURIET, A.; BILLOT, J. (1990). The main phenolics of fruits. In Fruit Phenolics; CRC Press: Boca Raton, FL; p. 1-98.

MILLER, G.A. Sucralose. In: NABORS, L.B.; GELARDI, R.C. (1991). Alternatives sweeteners. 2nd ed. New York: Marcel Dekker,. p.173-195.

MONTEIRO, F. S. (2011). Obtenção de suco de amora-preta (Rubus spp.) concentrado em antocianinas utilizando processos de separação por membranas. Dissertação (mestrado) Universidade Estadual de Campinas. Faculdade de Engenharia de Alimentos. Campinas, SP: [s.n].

MORENO-ALVAREZ, M. J.; MATOS, A. V.; LÓPEZ, E., BELÉN, D. (2002). Estabilidad de antocianinas em jugos pasteurizados de mora (Rubus glaucus Benth). ALAN, v. 52, n. 2, supl. 2, online.

OFEK, I.; GOLDHAR, J.; ZAFRIRI, D.; LIS, H.; ADAR, R.; SHARON, N. (1991). Anti-Escherichia coli adhesin activity of cranberry and blueberry juices. N Engl J Med;324:1599.

OSHIOKA, M.; SHIMOMURA, Y.; SUZUKI, M. Dietary polydextrose affects the large intestine in rats. J Nutr. 1994;124(4):539-47.

PENNINGTON, J. A. T. (2002). Food composition databases for bioactive food components. Journal of Food Composition and Analysis, San Diego, v. 15, n. 4, p. 419-434.

PFIZER Inc. (1978). Polidextrose food additive petition. New York: Pfizer Inc. (FDA petition 9A3441).

PRADO, A. (2009). Composição fenólica e atividade antioxidante de frutas tropicais. 107 p. Dissertação (Mestrado em Ciências de Alimentos) - Escola Superior de Agricultura "Luiz de Queiroz", Universidade de São Paulo, Piracicaba.

PREGNOLATTO, W.; PREGNOLATTO, N.P. (1985). Normas Analíticas do Instituto Adolfo Lutz: métodos químicos e físicos para análise de alimentos. São Paulo: Instituto Adolfo Lutz. v. 1, 533 p.

RASEIRA, M. do C. B.; SANTOS, A. M. dos. (1992). Caingangue, nova cultivar de amoreira-preta para consumo 'in natura'. Horti Sul, Pelotas, v. 2, n. 3, p. 11-12.

RODRíGUEZ, M. B. S.; MEGÍAS, S. M.; BAENA, B. M. (2003). Alimentos Funcionales y Nutrición Óptima. CERCA O LEJOS Revista Española de Salud Pública, v. 77, n. 3, p. 317-331. 
SAAD, S.M.I. (2006). Probióticos e prebióticos: o estado da arte. Revista Brasileira de Ciências Farmacêuticas, São Paulo, v. 42, n. 1, p. 1-16.

SÁNCHEZ-MORENO, C. (2002). Compuestos polifenólicos: efectos fisiológicos. Actividad antioxidante. Alimentaria, p.29-40.

SCHMIDT, D. R.; SOBOTA, A. (1988). An examination of the anti-adherence activity of cranberry juice on urinary and nonurinary bacterial isolates. Microbios. 55:173-81.

SCOTTI, L.; M.T. ; CARDOSO, C.; PAULETTI, P.; CASTRO-GAMBOA, I.; BOLZANI, V. S.; VELASCO, M. V. R.; MENEZES, C.M. S.; FERREIRA, E. I. (2007). Modelagem molecular aplicada ao desenvolvimento de moléculas com atividade antioxidante visando ao uso cosmético. Revista Brasileira de Ciências Farmacêuticas, vol. 43, n. 2.

SEERAM, N. (2008). Berry Fruits: Compositional Elements, Biochemical Activities, and the Impact of Their Intake on Human Health, Performance, and Disease. Journal of Agricultural and Food Chemistry, v. 56, n. 3, p. 627-629.

SIES, H.; STAHL, W. (1995). Vitamins E and C, beta-carotene, and other carotenoids as antioxidants. American Journal of Clinical Nutrition, v.62, n.6, p.1315-1321.

SILVA, S. M.S.; MURA J.D.P. (2007). Tratado de alimentação, nutrição e dietoterapia. São Paulo: Roca. p.77-112.

SINGHAL, REKHA S.; GUPTA, A. K.; KULKARNI, P. R. (1991). Low-calorie fat substitutes. Trends in Food Science \& Technology, Cambridge, v. 2, n. 10, p. 241-244, Oct.

STONER, G. D.; WANG, L. S.; CASTO, B. C. (2008). Laboratory and clinical studies of cancer chemoprevention by antioxidants in berries. Carcinogenesis, v. 29, p. 1665-1674.

STOTHERS, L. (2002). A randomized trial to evaluate effectiveness and cost effectiveness of naturopathic cranberry products as prophylaxis against urinary tract infection in women. Can J Urol; 9:1558-62.

STUMM, I.; BATLES, W. (1997). Analysis of the linkage positions in polydextrose by the reductive cleavage method. Food Chemistry, v. 59, n. 2, p. 291-297.

SWEETMAN, C.; WARDLE, J.; COOKE, L. (2008). Soft drinks and 'desire to drink' inpreschoolers. Int J Behav Nutr Phys Act; 5:60.

THEBAUDIN, J. Y.; LEFEBRE, A. C.; HARRINGTON, M.; BOURGEOIS, C. M. (1997). Dietary fibres: Nutritional and technological interest. Trends Food in Science \& Technology, Colney, v. 8, n. 2, p. 41-48.

TERMENTZI, A.; et al. (2006). Antioxidant activity of various extracts and fractions of Sorbus domestica fruits at different maturity stages. Food Chemistry, v. 98, p.599-608.

VENTURINI FILHO, W. G.; BARNABÉ, D.; SALATA, C. C. (2005). Tecnologia de Bebidas: Matéria-prima, processamento, BPF/APPCC, legislação e mercado. 1a ed. São Paulo: Edgard Blucher. 
WANG, L. S.; HECHT, S. S.; CARMELLA, S. G.; YU N.; LARUE, B.; HENRY, C.; MCINTYRE, C.; ROCHA, C.; LECHNER, J. F.; STONER, G. D. (2009). Anthocyanins in black raspberries prevent esophageal tumors in rats. Cancer Prevention Research, Phila Pa. v. 2, n. 1, p. 83-94.

WANG, W. D.; XU, S. Y. (2007). Degradation kinetics of anthocyanins in blackberry juice and concentrate. Journal of Food Engineering, v.82, p.271-275.

WILLETT, W. C. (2001). Eat, drink, and be healthy: the Harvard Medical School guide to healthy eating. New York: Simon and Schuster.

ZHONG, J.; LUO, B.; XIANG, M.; LIU, H.; ZHAI, Z.; WANG, T.; CRAIG, S. A. (2000). Studies on the effects of polydextrose intake on physiologic functions in Chinese people. Am J Clin Nutr;72 (6):15039.

ZINK, R. (2000, jun) Fabricação de balas duras, mastigávies e de goma ditet. In: Apostila do Seminário de Produtos Diet e Light, Campinas, 154 p. 